Borneo Journal of Sciences and Technology, Volume (1), Issue (2), Pages: 32-38

DOI: https://doi.org/10.35370/bjost.2019.1.2-05

e-ISSN: 2672-7439

(C) 2019, UCTS Publisher.

Submitted: $10^{\text {th }}$ April 2019

Accepted: $30^{\text {th }}$ April 2019

Published: $31^{\text {st }}$ July 2019

\title{
Determination of Sarawak's Brinjal Maturity Using Colour Image Processing Technique
}

\author{
Ting Huong Yong and Kimberly Tang Wen Wen \\ School of Computing and Creative Media, University College of Technology Sarawak, 96000 Sibu, \\ Sarawak, Malaysia
}

\begin{abstract}
Image processing techniques have been widely used as a non-destructive method to determine the maturity of agriculture products. In the past few decades, numerous fruit maturity grading systems have been proposed and developed. However, there is no system or technique is reported to determine the maturity for Sarawak's brinjal. Therefore, in this research, a colour image processing-based method is proposed in order to determine the maturity of Sarawak's brinjal based on the skin colour. Ripe Sarawak's brinjal has yellow or orange colour skin while unripe Sarawak's brinjal has green colour skin. The proposed method consists of four main phases which are image acquisition, image pre-processing, features extraction, and classification. CIELAB colour model is used in this proposed method. The RGB value extracted from the image is converted into CIELAB colour space in order to obtain the CIELAB value. The maturity of the Sarawak's brinjal is determined based on the colour difference between the fruit and the reference colour. In the experiment, a total of 48 Sarawak's brinjal sample with 24 sample for each grade (ripe and unripe) were prepared. 12 out of 24 samples from each grade were used for thresholding. From the experimental results, a total of 23 Sarawak's brinjals were correctly classified out of 24 Sarawak's brinjal sample, accounts for nearly $96 \%$ of accuracy.
\end{abstract}

Keywords: Sarawak's brinjal, maturity determination, colour image processing, CIE LAB

\section{INTRODUCTION}

\section{Sarawak's Brinjal}

Sarawak's brinjal locally known as Terung Asam, Terung Dayak or Terung Iban in the Malay language. It is a round or oval shape fruits with a sour taste. Sarawak's brinjal is one of the popular native vegetable in Sarawak [1] and it is widely grown in hill paddy in rural Sarawak. It belongs to the lasiocarprum species in Solanum genus from the Solanaceae plant family. The botanical name of Sarawak's brinjal is Solanum lasiocarpum Dunal [2,3]. Other common names of Sarawak's brinjal are mao qie in Chinese and ma uek in Thai [4].

The height of Sarawak's brinjal plant is around $100 \mathrm{~cm}$ to $250 \mathrm{~cm}$ [5]. The flower of the plant is white in colour and will develop into Terung Asam fruits. The shape of the fruits turns from round to oval as it grows bigger. Initially, the fruits are green in colour in the unripe stage as shown in Figure 1. Unripe Sarawak's brinjal fruits will turn from green into normally yellow to orange when ripe as shown in Figure 2 [1]. However, different varieties of Sarawak's brinjal will have different mature fruit's skin colour such as purplish black, brownish black, reddish orange, orange, and yellow $[1,6]$.

Sarawak's brinjal is one of the registered products of Sarawak under the Geographical Indications (GI) certificates. GI certificate is a form of product branding [1]. The authenticity, consistency and quality of the products are ensured under the protection of GI. This certificate adds value to Sarawak's brinjal and effectively increase the income of farmers and subsequently create greater demand both at home and abroad [7]. Sarawak's brinjal was initiatively file by the Department of Agriculture Sarawak under Geographical Indications (GI) certification in 2010 and was granted the GI certificate (No. GI2010-00002) on 30 June 2011 by the Malaysian Intellectual Property Organisation (MyIPO) [1, 5]. It was registered as "terung asam Sarawak" in the GI certificate [2].

Besides, Sarawak's brinjal could bring profitable income to the farmers in Sarawak. In the year of 2017, assistant agriculture officer Francis Musa said that the price of Sarawak's Brinjal cost between RM6 to RM 10 per kilogramme. A net profit of RM 134,313 would be generated from a low production of 16,000 fruits sold at RM10 per kilogramme. The farmers in Sarawak could earn RM 204,323 and above with a high production of 23,000 fruits from each harvest cycle and 
sold at the price of RM10 per kilogramme [3]. Sarawak's brinjal can be developed into value-added products such as jam, juice, dehydrated slices, spicy sambal, cakes, and ice cream [3, 8].

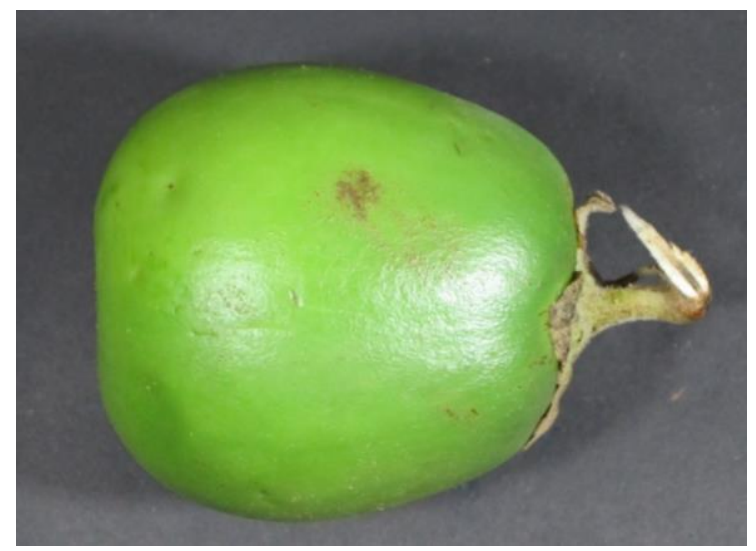

Figure 1: Unripe Sarawak's Brinjal

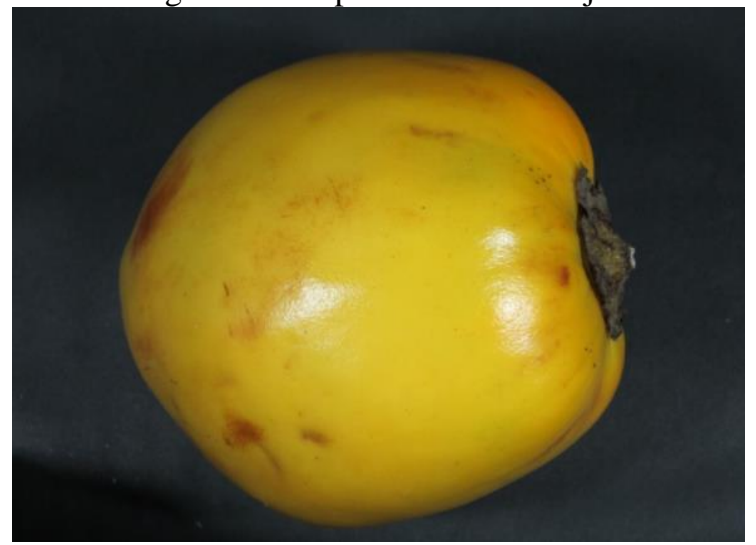

Figure 2: Ripe Sarawak's Brinjal

\section{Colour Model}

Colour model is an abstract mathematical model describing an approach to represent colours by tuples of numbers such as RGB or CMYK [9]. Colour space is a specific organization of colours. Each specific colour model can have different colour spaces. Colour space is represented in the three-dimensional coordinate system. In the three-dimensional system, each colour is represented by a single point. To apply colour as a visual cue in computer vision applications, image processing and multimedia, an appropriate approach to represent the signal of colour is required. Colour space provide a reasonable approach to recognize order, affect and effectively display the colours of the object taken into consideration. The problem's declaration and the solution can be addressed by choosing a suitable colour model. The knowledge about the way colour signals generated and what information needed from the colour signal is important during the colour model selection process. There are several usages of the colour model such as identify the categories of colour for a number of applications, judging the similarity and discriminate between colours and define the colours.

Colour models can be categorized into three categories, device-dependent colour model, useroriented colour model, and device-independent colour model. The device-dependent colour model also known as a device-oriented colour model. The resulting colours are depending on the device used to display it. Different devices will produce different colour for the same original. Device dependent colour spaces are widely applied in the application that require consistency between the colour and the hardware device. Colour models such as RGB and CMYK are device dependent. User-oriented colour models work as a connection between the human operator and the device used to handle the colour information. It is experimental approximate to the human colour perception [10]. It enables a human operator to express and describe the perception of the colours. Device independent colour model is opposite to device dependent colour model. As the name suggested, the resulting colour does not depend on the device used to display the colour. The characteristic of the device does not affect the colour produced. This type of colour space is used in colour management system. Colour models such as CIELAB, CIEXYZ, and HSV are device independent. Colour management system can eliminate, or at least reduce the colour difference between the devices [11].

In the past few decades, different type of colour models has been used to determine the maturity of the agricultural products. Colour image processing techniques have been widely used as a non-destructive method to identify the maturity of agriculture products. Those agriculture products include tomatoes, pineapples, mangoes, limes, lemons, persimmon fruits, guava, dates, melons, and bananas. Colour model such as CIELAB has been used by Opeña \& Yusiong (2017) to classify the tomatoes based on the maturity level and used by Lara-espinoza et al. (2016) in developing the guava classification system to classify the maturity of guava fruit $[12,13]$.

\section{Purpose of Study}

The purpose of this study is to design and develop a colour classification algorithm to determine the maturity of Sarawak's brinjal using image processing technique. A non-destructive method is proposed to determine the maturity of Sarawak's brinjal based on the colour information of the skin.

\section{MATERIALS AND METHODS}

In this proposed method, the maturity of Sarawak's brinjal is graded based on the skin colour. A nondestructive method is proposed to determine the 
ripeness of the Sarawak's brinjal without damage to the surface of the fruit. There are four main stages involved in this proposed Sarawak's brinjal maturity grading method which are image acquisition, image preprocessing, feature extraction, and classification. The flowchart of the proposed method is as shown in Figure 3.

\section{Image Acquisition Stage}

All of the Sarawak's brinjal samples used to determine the threshold value for maturity classification and used in the experiment are collected from the local fruit stalls. In this project, the Sarawak's brinjals are classified into ripe and unripe. A total of 24 Sarawak's brinjal samples are used to determine the threshold value for maturity classification. Each grade (ripe and unripe) consists of 12 Sarawak's brinjal. In this stage, the Sarawak's brinjal samples are captured under a controlled environment. The images of the 24 Sarawak's brinjal samples are captured in an imaging chamber. The imaging chamber used in this project was designed and developed by Mr Dennis Pao Kao Wei from UCTS.

The source of illumination in the imaging chamber is provided by using a pair of light bulbs with a colour temperature of 6500K. A Canon PowerShot S90 digital camera with 10.0 megapixels is used to capture the Sarawak's brinjal samples. The colour images of Sarawak's brinjal captured by the digital camera are saved in JPEG format and stored in a laptop running on Windows 10 operating system, Intel Core M processor with $1.20 \mathrm{GHz}$ of clock speed, and 8GByte of RAM.

\section{Image Pre-processing Stage}

The second stage of this proposed method is image preprocessing. The purpose of conducting this stage is to remove the unwanted region from the image. The unwanted regions are the background of the image, light spots and brown spots on the Sarawak's brinjal, fruit and the fruit pedicel. The region of interest is the Sarawak's brinjal fruit without light spots, brown spots, and fruit pedicel. In this stage, the colour image of Sarawak's brinjal is first converted into green channel grayscale image and then converted into a binary image. The binary image is used as a binary mask for the original colour image. Lastly, the masking operation is carried out by applying the binary mask onto the original colour image in order to remove the unwanted regions in the image. The image pre-processing process for the image of unripe Sarawak's brinjal and ripe Sarawak's brinjal is as shown in Figure 4 and 5 respectively 


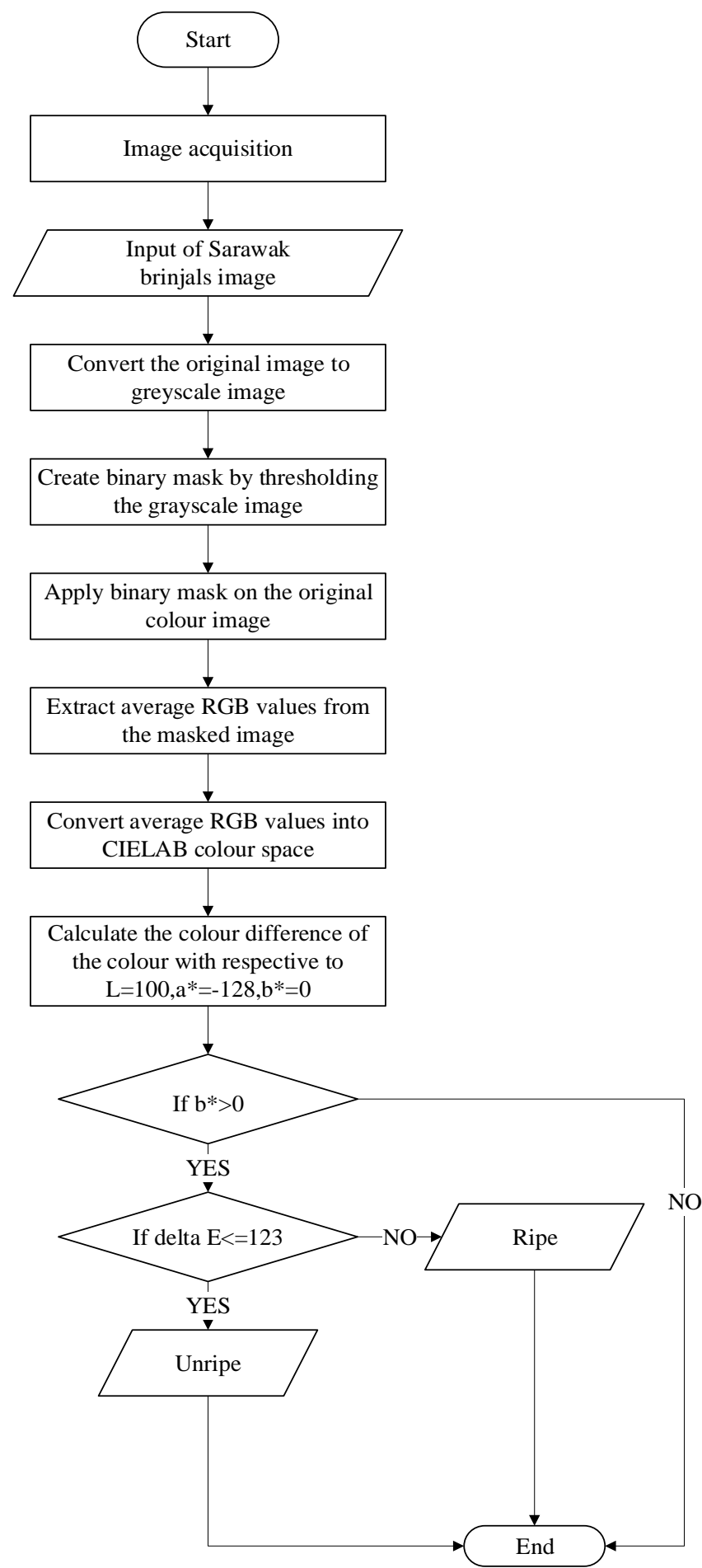

Figure 3: Flowchart of the Proposed Method 

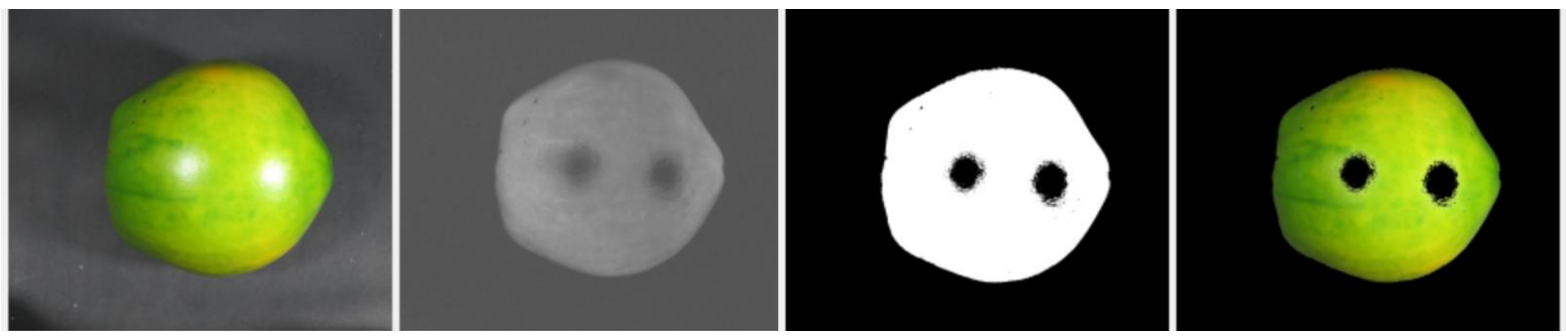

Figure 4: Removal of Unwanted Region in the Image of Unripe Sarawak's Brinjal
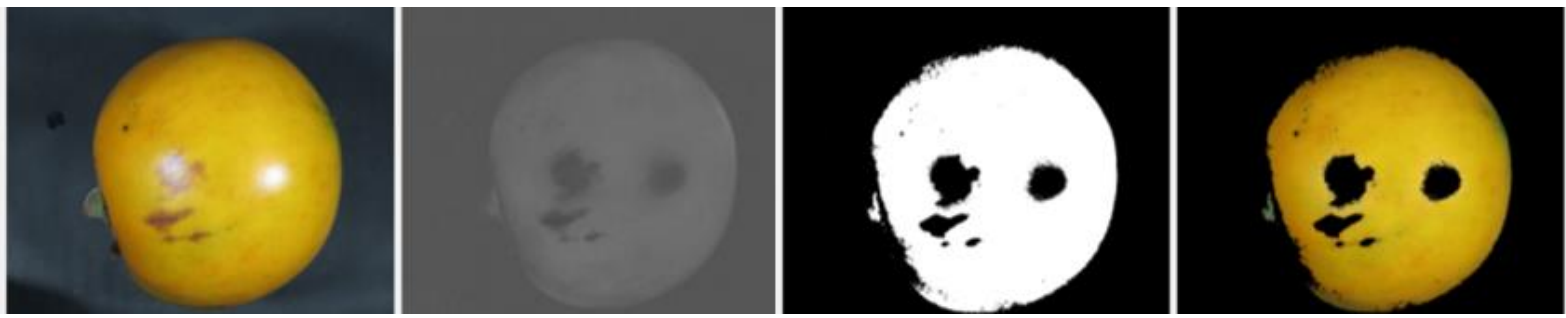

Figure 5: Removal of Unwanted Regions in the Image of Ripe Sarawak's Brinjal

\section{Features Extraction Stage}

In this stage, the RGB values of each colour pixels in the masked image are extracted except the black colour pixels with RGB values of $(0,0,0)$. RGB values of the black colour pixel are neglected because it does not contain any wanted colour information. This can reduce the processing time as only colour pixels are taken into consideration. The average RGB value of the masked image is calculated and then converted into CIELAB colour space. The CIELAB values are used to determine the maturity of the Sarawak's brinjal. Converting from RGB to CIELAB colour space is a two steps process. The first step is to convert the average RGB value into $X Y Z$ value. The second step is to convert the XYZ values into CIELAB values.

\section{Classification}

In this proposed method, the maturity of Sarawak's brinjal is determined based on the colour difference between the Sarawak's brinjal and the reference colour with CIELAB values of $\mathrm{L}=100, \mathrm{a}^{*}=-128$, and $\mathrm{b}^{*}=0$. The colour difference is calculated by using the Delta $\mathrm{E}$ equation as seen in Eq. 1 [14]. The colour difference is used as the threshold value for Sarawak's brinjal ripeness classification. The threshold value is 122.9493 $\Delta \mathrm{E}$ unit which is approximate to 123 unit. The Sarawak's brinjal with colour difference less than or equal to 123 unit will be classified as unripe and vice versa.

$$
\Delta E=\sqrt{\left(\Delta L^{*}\right)^{2}+\left(\Delta a^{*}\right)^{2}+\left(\Delta b^{*}\right)^{2}}
$$

The threshold value of $123 \Delta \mathrm{E}$ unit is obtained by thresholding a total of 24 Sarawak's brinjal samples with 12 samples for each grade (ripe and unripe). The images of the samples were pre-processed and the average RGB values are extracted and converted into CIELAB colour space. The CIELAB values for each sample were recorded. The maximum CIELAB values for each grade was obtained and used to calculate the colour difference between the grade and the reference colour. The maximum $\Delta \mathrm{E}$ unit for each grade is as shown in Table 1.

\section{RESULTS AND DISCUSSION}

A total of 48 Sarawak's brinjal's sample with 24 samples for each grade (ripe and unripe) were prepared. 12 out of 24 samples from each grade were used for thresholding. Another 12 samples from each grade were used in the experiment and graded by using the proposed method. In the experiment, a total of 23 out of 24 Sarawak's brinjal samples were correctly classified.

All of the ripe Sarawak's brinjal samples used in the experiment were correctly classified. The success rate of classifying ripe Sarawak's brinjal is $100 \%$. The 12th unripe Sarawak's brinjal sample is misclassified as ripe. 11 out the 12 unripe Sarawak's brinjal samples are correctly classified by the proposed method. The success rate of classifying unripe Sarawak's brinjal is $91.67 \%$. An average success rate of $95.83 \%$ is achieved by the method proposed. The results of Sarawak's brinjal maturity determination are summarised in Table 2. 
Table 1: Maximum $\Delta \mathrm{E}$ Unit for Each Sarawak’s Brinjal Samples Grade

\begin{tabular}{|l|c|}
\hline \multicolumn{1}{|c|}{ Sarawak's Brinjal Grade } & Maximum $\Delta$ E unit \\
\hline Ripe & 154.0170 \\
\hline Unripe & 122.9493 \\
\hline
\end{tabular}

Table 2: Results of Proposed Method for Determining the Maturity of 24 Sarawak's Brinjal Samples

\begin{tabular}{|l|c|c|c|c|}
\hline Grade & Sample Images & Correct & Incorrect & Accuracy \\
\hline Ripe & 12 & 12 & 0 & $100 \%$ \\
\hline Unripe & 12 & 11 & 1 & $91.67 \%$ \\
\hline \multicolumn{2}{|c|}{ Average } & $95.83 \%$ \\
\hline
\end{tabular}

\section{CONCLUSION}

In this paper, a colour classification algorithm was designed and developed to determine the maturity of the Sarawak's brinjal. An experiment was conducted to evaluate the accuracy of the proposed method. In the experiment, a total of 24 Sarawak's brinjal samples were used and 23 out of 24 Sarawak's brinjal samples were classified correctly. An average accuracy rate of $95.83 \%$ is achieved by the proposed method.

The accuracy of the proposed method can be improved by increasing the amount of Sarawak's brinjal sample used for thresholding. This is to determine the maximum boundary of the CIELAB values of unripe Sarawak's brinjals and ripe Sarawak's brinjals. One out of 12 unripe Sarawak's brinjal sample is misclassified as unripe because of the colour difference between the sample and the reference colour exceeds the threshold value of $122.9493 \Delta E$ unit. More Sarawak's brinjal samples are required for thresholding in order to find out the possible maximum colour difference between unripe Sarawak's brinjals and the reference colour and the possible maximum CIELAB values.

\section{Limitation of Proposed Method}

The accuracy of the proposed method will be influenced by the amount of Sarawak's brinjal sample that used for thresholding. Currently, the proposed method is unable to detect the defects, such as bruising, insect holes, fungi attack, rot and growth defects on the Sarawak's brinjal. Currently, proposed method may include those defects as calculation parameters and eventually degrade the classification accuracy. Additionally, other agriculture products with colour difference within the threshold value will be misclassified as unripe Sarawak's brinjal and vice versa.

\section{Future Work}

In future, more Sarawak's brinjal sample will be collected and used for thresholding to improve the accuracy of the proposed method. Shape detection, defect classification and object recognition algorithms will be designed and developed to overcome the limitation of this proposed method.

\section{ACKNOWLEDGMENT}

The authors would like to acknowledge Mr. Koh Chen Chung and Ms. Hwong Chia Shing for supplying raw Sarawak's Brinjal samples.

\section{REFERENCES}

[1] Umar, S. (2013). 'Terung Asam Sarawak', a Geographical Indications (GI) - Registered Product of Sarawak.

[2] Chan, Z. (2013, November 30). Jabu: More R\&D to unearth hidden qualities of popular terung asam S'wak - Community | The Star Online. The Star Online. Retrieved from https://www.thestar.com.my/news/community/201 3/11/30/uniquely-qualified-to-succeed-jabu-morerd-to-unearth-hidden-qualities-of-popular-terungasam-swak/

[3] Sman, C. (2017, May 19). 'Terung asam Sarawak can bring lucrative income' - BorneoPost Online | Borneo, Malaysia, Sarawak Daily News | Largest English Daily in Borneo. BorneoPost Online. Retrieved from http://www.theborneopost.com/2017/05/19/terungasam-sarawak-can-bring-lucrative-income/

[4] U.S. National Plant Germplasm System. (2017). Taxon: Solanum lasiocarpum Dunal. Retrieved December 17, 2017, from https://npgsweb.arsgrin.gov/gringlobal/taxonomydetail.aspx?416240

[5] Razili, R. M., Umar, S., \& Sallehuddin, R. (2015). Quality Product from Terung Asam (Solanum Lasiocarpum Dunal): a Popular Indigenous Fruit- 
Vegetable of Sarawak, Malaysia. Acta Horticulturae, (1088), 569-572. https://doi.org/10.17660/ActaHortic.2015.1088.104

[6] Malaysia Vegetarian Food. (2013). Terung Dayak - Malaysia Vegetarian Food. Retrieved December 17, 2017, from http://www.malaysiavegetarianfood.com/tag/terung -dayak/

[7] Ruekeith, G. O. (2011, October 6). Sarawak Dabai and Terung Asam get (GI) protection. BorneoPost Online. Retrieved from http://www.theborneopost.com/2011/10/06/sarawa k-dabai-and-terung-asam-get-gi-protection/

[8] The Malaysian Entrepreneurs Festival. (n.d.). Retrieved May 24, 2018, from http://www.tmef.com.my/sme-newsdetails.php?id=418

[9] Kaur, K., \& Sahib, F. (2015). CASE STUDY OF COLOR MODEL OF. International Journal of Computer Engineering and Technology, 6(12), 6064.

[10] Kelda, H. K., \& Kaur, P. (2014). A Review: Color Models in Image Processing. International Journal on Computer Technology \& Applications, 5(2), 319-322.

[11]Enfocus BVBA. (2011). Device-independent color. Retrieved from http://www.enfocus.com/manuals/ReferenceGuide/ PP/10/enUS/en-us/concept/c_aa1141508.html

[12] Opeña, H. J. G., \& Yusiong, J. P. T. (2017). Automated tomato maturity grading using $\mathrm{ABC}$ trained Artificial Neural Networks. Malaysian Journal of Computer Science, 30(1), 12-26.

[13] Lara-espinoza, E. M., Trejo-duran, M., Lizarragamorales, R. A., Cabal-Yepez, E., \& Saldana-Robles, N. (2016). Determination of the Ripeness State of Guavas Using an Artificial Neural Network. Research in Computing Science, 121, 105-111.
[14] Cárdenas-Pérez, S., Chanona-Pérez, J., MéndezMéndez, J. V., Calderón-Domínguez, G., LópezSantiago, R., Perea-Flores, M. J., \& ArzateVázquez, I. (2017). Evaluation of the ripening stages of apple (Golden Delicious) by means of computer vision system. Biosystems Engineering, 159 , 46-58. https://doi.org/10.1016/j.biosystemseng.2017.04.00 9 